\title{
Sandor PAPER Bilingualism in EYS in the Eyes of a Bilingual Educator
}

\author{
Judit Sandor \\ My School Ticino - Scuola bilingue 0-10, Switzerland
}

\begin{abstract}
Parents often seek advice from pediatricians and early education professionals on what to teach their children in a bilingual household. The most common questions are, "Should I introduce a second language to my child? Is this going to confuse my child? This paper will give parents and educators a clear answer to these questions proved by many research and statistics. It will also give an overall idea of how to behave in a bilingual environment, giving them methods of teaching and ways of exercising bilingualism with their children in or outside the family environment. In this paper I also discuss not just the importance of learning a second language from a very young age, but also, how important it is to teach a new culture alongside the second language itself. I have used Qualitative and online researches. Working in this sector for eight years, I also had the opportunity to participate in many courses held by experts in bilingualism. According to statistics, $40 \%$ of all adults across the globe are monolingual, $43 \%$ are bilingual, $13 \%$ are trilingual and $4 \%$ can speak 4 or more languages fluently. By these statistics alone, those who speak only one language are already in the minority. What does this mean for a child? Well, being in the language minority will most certainly limit the opportunities available to the child as he/she reaches adulthood. By limiting their ability to communicate on a multilingual basis, it is simultaneously limiting their qualifications for future successes.
\end{abstract}

Keywords: bilingualism, young age, culture, education, experience

\section{Introduction: What are the concerns regarding bilingual education?}

Parents often seek advice from pediatricians and early education professionals on what to teach their children in a bilingual household. The most common questions are, "Should I introduce a second language to my child? Is this going to confuse my child? Is it going to cause problems when he/she will start reading and writing?

\subsection{Language and Communication.}

1.1.1 By now it's pretty much common knowledge that reading to young ones is a fundamental tool, as is having frequent conversations with them. These key components teach children the basics for language and communication foundations that will stay with them for the rest of their lives.

If we take these two components in consideration regarding communication and language development, we see how it affects the skills of a child having these basic foundations. Expanding that learning base by adding additional languages only make the child's knowledge and foundations richer. Bilingual education - the act of learning two or more 


\section{2nd World Conference on Teaching and Education}

\section{9-21 February, 2021}

Vienna, AUSTRIA

languages simultaneously - is growing in popularity across the globe in recent decades because of this theory.

\subsubsection{Bilingualism, its advantages in all aspects of life.}

According to the U.S. Department of Education, "Learning more than one language is an asset to individuals, families, and our entire society."

Bilingual children learn better and faster than other children. Why?

Because children who begin learning second languages before the age of six will have an easier time understanding math concepts and solving word problems; developing strong thinking skills; using logic; focusing; remembering and making decisions, in other words having a faster problem solving skill.

In my experience children who are bilingual are not just more likely to have better study reports, they are also taking examinations with more ease and less stress than other children.

When we talk about bilingualism, we aren't just talking about learning another language in an A level. We are talking about knowing fluently another language, knowing another culture and the origin for that language. This opens the door for these young learners to be able to live in a different country, have the ABILITY of accepting another culture and being ABLE to live with those within that culture. life.

These skills make a person richer and more stable. He/she will have more opportunities in

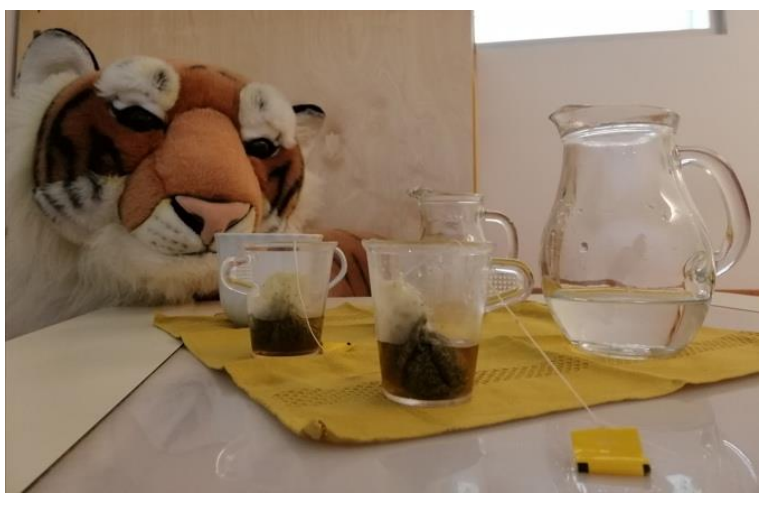

“THE TIGER WHO CAME TO TEA” story time 


\section{2nd World Conference on Teaching and Education}

\section{9-21 February, 2021 Vienna, AUSTRIA}

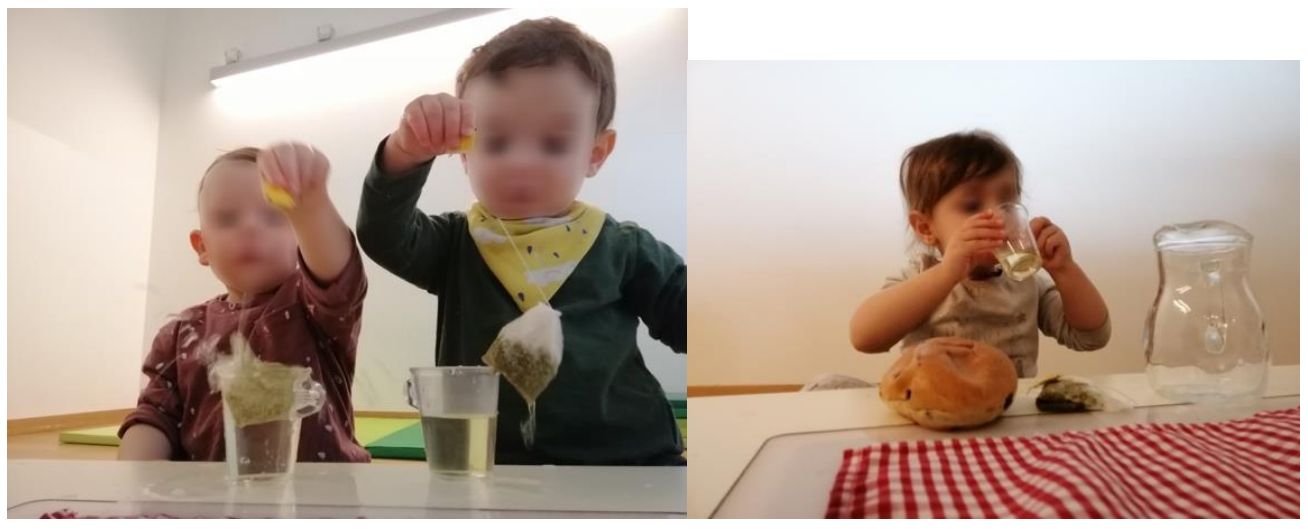

Italian- Swiss children learning about English Tea Time

\section{Body: Cognitive Development}

Becoming bilingual serves as a means to sharpen (not confuse) young minds. Essentially, it helps children form a basis for processing more complex tasks and learning processes throughout the rest of their lives. Bilingualism builds a solid (and organized) foundation of cognitive development when introduced during early childhood education. The earlier the better.

It is very well observable that children will be more switched on, and their skill of problem solving will be much faster than a child who only speaks one language.

The capability of problem solving is the key to success in life.

\subsection{Social-Emotional Development}

By embracing the multilingual and multicultural approach outside of family doors, communities grow tighter. Why?

Because there is communication, which leads to understanding between one another, not only, it also leads to respecting each other's cultural background.

Being bilingual supports children in maintaining strong ties with their family, culture, and community. These children are also able to make new friends and create strong relationships using their second language.

By understanding and speaking more languages one is more able to connect to individuals coming from different places, having the opportunity to be part of more communities. For a child it means being able to change schools - when moving to a different country - without having a big linguistical problem.

Regarding moving abroad, it is also a very known fact that a bilingual child/person is able to learn a $3^{\text {rd }}$ language in a very short amount of time. 


\section{2nd World Conference on Teaching and Education}

19-21 February, 2021

Vienna, AUSTRIA

In addition to building community relations, research has also shown, bilingual children learn better focus and self-control at critical developmental stages.

\subsection{Some successful actions I use with the children, and how I created a bilingual environment}

First, I treat children as young adults. Speaking to them in a normal tone of voice just as I would speak to any of my colleagues. The only difference being, that I simplify my speech with them.

I do not use terms which I know they would not be able to understand. It is also very important to be visual with children when teaching a new language at a young age. Do not expect them to know words you haven't shown them or made them understood.

More than $80 \%$ of my students are speaking only one language at home. In my case the majority of these students speak Italian. English is their second language, which they are currently learning at school. I'm an educator, in our section, we have children from 13-24 months old. They are in the phase of learning to speak and expressing themselves. What is positive about this group is that, I know that these children by the age of 3 , will be fluent in two languages. The hardest part is to simplify everything I do with them.

So, the first thing I did to create the bilingual environment (alongside with my Italian speaking colleagues) is to designate a corner where only English "activities" occur. It is obvious that children can't distinguish at this age what's Italian or what's English. They can notice the difference between languages by the sounds and the melodies. In our school, we operate on the basis of 1 person 1 language. It means that person $\mathrm{X}$ speaks only $\mathrm{X}$ language and person Y only speaks Y language. In my case, I, Judit Sandor, speak only in English with the children. This is to help them differentiate the two languages. I sit and play with them throughout the day.

There are times when I just observe the children, to see what they like to play with, how they interact with each other in the different settings, etc.

This way I can see their interests, and I build my simple, useful activities around these observations.

In the nursery songs work fantastically! Music helps a lot in language learning. Singing nursery rhymes is the key of my success with this age group. I start to introduce the sounds to the letters, using Jolly music with them. It's never too early to teach the children the right pronunciations of the sounds and build their phonic awareness. They love music; so, they will sit with you and listen.

Whenever I sing with the children, I use a blackboard where I stick the images of the main characters, introducing them one by one, this way they can connect the spoken words with the images. I also use actions for each song.

It is CRUTUAL for them to understand what you are talking about. Otherwise they will lose interest, as well as one cannot learn if he/she has words he/she doesn't understand. It's quite logical if you think about it. 


\section{2nd World Conference on Teaching and Education}

\section{9-21 February, $2021 \quad$ Vienna, AUSTRIA}

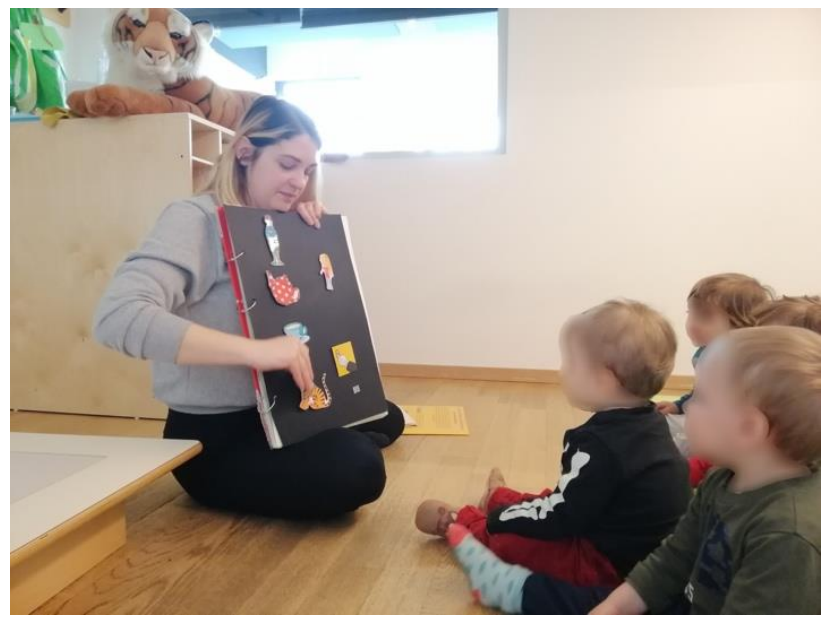

Sory telling using a black background to enhance colored figures.

What is also very important with young learners is to be patient. There are days when I have to repeat the same sentences or words over and over again. Children learn from repetition.

With older kids (age 3-5), I use more or less the same methods, just proposing more complicated rhymes, songs, stories and activities. At this age group their attention span is much longer, and as a teacher you should always take advantage of that.

I have met many 3, 4-year old's who kept telling me that they don't like English (second language). The only reason they will say such thing is because there are words you've said they don't understand, so they are not able to follow your instructions and activities. Be visual, show them in some way what you are talking about.

These students of mine "who did not like English "are now the brightest ones in the class.

Lastly, I wanted to share, just how important it is to introduce a different culture alongside the new language. Children are fascinated by new people and cultures. I always do something which reminds them of where the language comes from. You can introduce typical or traditional food. Children love to dress up in traditional clothes, learn traditional dances etc. Always do your research and experience for yourself the culture which you want the children to be part of or experience.

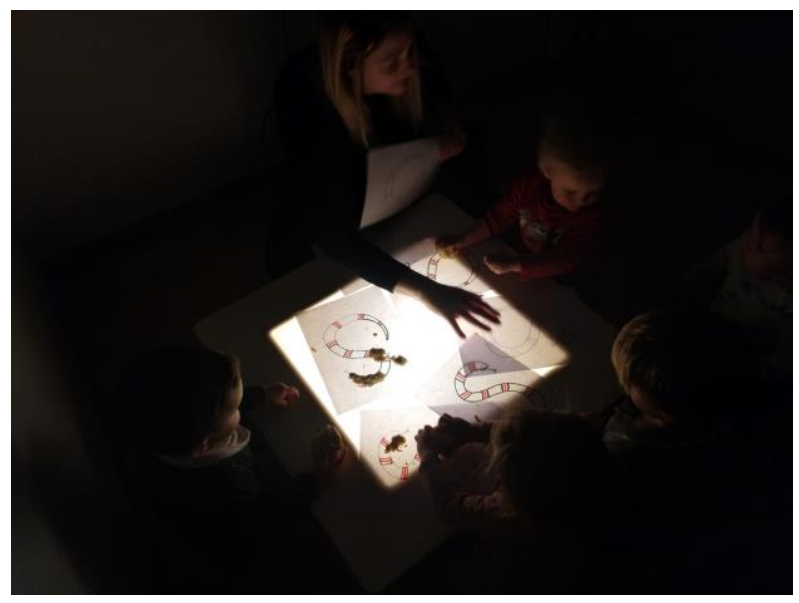




\section{2nd World Conference on Teaching and Education}

\section{9-21 February, $2021 \quad$ Vienna, AUSTRIA}



Fun with Phonics

\section{Conclusion: Long-Term Success}

If you want to grasp the kind of impact a bilingual education will have on your child, look at current demographics. According to statistics, $40 \%$ of all adults across the globe are monolingual, $43 \%$ are bilingual, $13 \%$ are trilingual and $4 \%$ can speak 4 or more languages fluently. By these statistics alone, those who speak only one langue (English, Italian, ... etc.) are already in the minority.

What does this mean for your child? Well, being in the language minority will most certainly limit the opportunities available to your child as they reach adulthood. By limiting their ability to communicate on a multilingual basis, it is simultaneously limiting their qualifications for future successes.

Bilingual and biliterate adults have more job opportunities than monolingual. They have the opportunity to participate in the global community in more ways, get information from more places, and learn more about people from other cultures.

Overall, more and more researchers are proving that introducing additional languages at an early age has an immensely positive impact on children. It leads them to become more successful and confident in life.

\section{Acknowledgment}

This paper is an output of a re-search on bilingualism.

It has become one of the biggest "fashions" all around Europe and now also outside of Europe, to send our children to a bilingual school, where they can learn to speak a second language fluently from a very young age.

This world is big, united nations are big. What is observable is that we are made of many different countries, cultures, languages and traditions which we must all bring together by 


\section{2nd World Conference on Teaching and Education}

19-21 February, 2021

Vienna, AUSTRIA



loving and understanding each other. However, it cannot occur unless we learn each other's languages, respect each other's cultural background, and learn each other's traditions. We are all seeking for world peace, which is the ideology of universal global understanding. This is how we can achieve it.

I would like to thank to my very first school Director, who had given me the opportunity to work with children and become an Educator.

I would also like to thank my friends and colleagues, who are always keeping me on my toes by giving constructive criticism, to make sure I always do my best.

Last but not least I also like to thank my current CEO, who has been pushing me as well as all the staff to step up our game and learn more about bilingualism.

\section{References:}

(Book)

Emotional Learning, emotional teaching

(Mohwickel, 21 ${ }^{\text {st }}$ of Feb 2011)

author: Elisabetta Mohwinckel

\section{(Trainings)}

Jolly Phonics

( L'albero di Momo )

English Teaching techniques ( EYS )

( Trainer; Lucy Costa British

Council )

Jolly Music

London )

Jolly Toddlers

Madrid )

( Trainer; Beki Wilson,

30 hrs Training on Bilingualism

Mohwinckel)

(Coach; Elisabetta

\section{(Online Sources style)}

Krista Byers-Heinlein (B.A., McGill University; M.A., Ph.D., University of British Columbia)

Available: https://www.ncbi.nlm.nih.gov/pmc/articles/PMC6168212/

\section{Rismareni Pransiska}

(Department of Early Childhood Education, Faculty of Education, Universitas Negeri Padang) Available:

https://www.researchgate.net/publication/312866228_Benefits_of_Bilingualism_in_Early_Ch ildhood_A_Booster_of_Teaching_English_to_Young_Learners

Michigan State University 


\section{2nd World Conference on Teaching and Education}

Available: https://www.canr.msu.edu/news/advantages_of_a_bilingual_brain

\section{My presentation}

My name is Judit Sandor, I'm originally from Hungary, currently living in Italy and work in

Switzerland.

I am triliterate bilingual educator. I speak Hungarian, English, Italian.

I have been working in this sector for 8 years now and have been a bilingual teacher/educator for over 7 years. In this essay I will share some very interesting facts on the subject of bilingualism in early years, as well as sharing some of my personal experiences with children. 